Jurnal Luminous 02 (2) (2021) 1-6

Riset IImiah Pendidikan Fisika

Vol. 2 No. 2 (2021) hal 1-6
E-ISSN 2715-6990

P-ISSN 2715-9582

072021

https://jurnal.univpgri-

palembang.ac.id/index.php/luminous

\title{
ANALISIS PEMAHAMAN KONSEP SISWA DENGAN STRATEGI READING INFUSION
}

\author{
Bayu Sugara', Yudi Kurniawan ${ }^{2}$, Riski Muliyani ${ }^{3}$ \\ ${ }^{123}$ Prodi Pendidikan Fisika STKIP Singkawang, JI. Naram, Singkawang Utara, Kalimantan Barat, 79151 \\ 1bayusugara971@gmail.com, ${ }^{2}$ yudikurniawan1012@gmail.com, ${ }^{3}$ kikiriski1012@gmail.com
}

Received: 3004 2021. Accepted: 2907 2021. Published: 072021

\begin{abstract}
Abstrak
Penelitian ini bertujuan untuk mendeskripsikan pemahaman konsep siswa dengan strategi reading infusion. Penelitian yang digunakan adalah deskriptif kuantitatif. Populasi dalam penelitian ini adalah seluruh siswa kelas VIII disalah satu SMP Negeri Kabupaten Sambas. Sampel penelitian diambil secara Convenience Sampling yaitu siswa kelas VIII A disalah satu SMP Negeri Kabupaten Sambas. Hasil penelitian menunjukan bahwa: 1) rata-rata pemahaman konsep siswa sebesar 67,22 dan dari 30 siswa yang mengikuti tes hanya 13 siswa yang memahami konsep sedangkan 17 siswa lainnya tidak memahami konsep. 2) Hasil wawancara yang dilakukan pada 13 orang yang memahami konsep menggambarkan bahwa siswa tertarik dengan reading infusion serta berminat pada bahan bacaan sedangkan 17 siswa lainnya juga tertarik dengan reading infusion serta berminat pada bahan bacaan, akan tetapi masih mengalami kesulitan dalam memahami konsep. Diharapkan untuk peneliti selanjutnya yang menggunakan strategi reading infusion dalam pelaksanaan pembelajaran agar dipadukan dengan strategi lain agar siswa lebih mudah dalam memahami konsep.
\end{abstract}

Kata Kunci: Analisis, pemahaman konsep, reading infusion

(C) 2021 Pendidikan Fisika FKIP UPGRI Palembang

\section{PENDAHULUAN}

Pembelajaran IPA di SMP/MTs menuntut siswa mampu memahami konsep, menunjukan sikap ilmiah, mengajukan pertanyaan serta melakukan pengamatan tentang alam sekitar dan mampu menyajikan data hasil pengamatan secara sederhana (Peraturan Menteri Pendidikan dan Kebudayaan Nomor 21 Tahun 2016 Tentang Standar Isi Pendidikan Dasar dan Menengah, 2016). Pada pembelajaran IPA, khususnya fisika pemahaman konsep sangat penting untuk dilatihkan (Mariana, 2017). Pentingnya pemahaman konsep untuk dilatihkan karena siswa tidak hanya memahami konsepnya saja melainkan juga dapat menjelaskan kembali materi yang diperolehnya dengan kalimat sendiri serta penerapannya dalam kehidupan sehari-hari (Nahdi et al., 2018). Dengan demikian, maka pembelajaran IPA disekolah harus melatihkan pemahaman konsep. Pemahaman konsep adalah kemampuan siswa dalam menafsirkan, mencontohkan, mengklasifikasikan, merangkum, menyimpulkan, membandingkan, dan menjelaskan dari informasi yang diperoleh, baik yang bersifat lisan, tulisan, ataupun grafis, yang disampaikan melalui pengajaran, buku, atau layar computer (Lorin W. Anderson \& Krathwohl, 2010). Menurut 
(Kusumawati et al., 2019) siswa yang memiliki kemampuan memahami konsep adalah siswa yang dapat menyelesaikan masalah dengan berbagai variasi.

Kalimantan Barat telah melaksanakan program belajar dari rumah (BDR) karena covid-19 sejak tanggal 16 maret 2020 hingga waktu yang tidak bisa ditentukan pada jenjang SMP Sutarmidji (SUARA KALBAR) Dina Prihatini Wardoyo 2020). Subhan menjelaskan bahwa kapan siswa-siswi dapat memulai belajar disekolah masih menunggu kebijakan pemerintahan pusat sehingga BDR disambas tetap diberlakukan (Suara Pemred) 2020). Dinas pendidikan Kalimantan barat Herman menyatakan saat proses BDR dilakukan masih mengalami hambatan seperti tidak meratanya jaringan internet sehingga mengakibatkan proses BDR tidak optimal dan mata pelajaran yang disampaikan tidak bisa tuntas (Rendra Oxtora, 2020). Lembaga penjaminan mutu pendidikan (LPMP) juga sudah melakukan kajian sebagai evaluasi BDR, kemudian menemukan beberapa kendala, seperti jarak siswa yang sangat jauh, siswa berada di pedalaman, ladang hingga kebun sehingga mengalami kesulitan sinyal, belum lagi orang tua yang tidak memiliki HP maupun laptop, dan termasuk guru tidak memiliki kesiapan dalam BDR Suprianus (Rendra Oxtora, 2020). Hal ini juga ditemukan pada salah satu SMP Negeri Kabupaten Sambas yang melaksanakan program BDR, dalam pelaksanaan BDR beberapa kendala juga ditemukan seperti sinyal yang tidak mendukung, orang tua yang tidak memiliki HP, jarak siswa yang jauh karena pembelajaran luar jaringan (luring), dan ketidak tersediaan kuota internet juga menjadi masalah sehingga menyebabkan pemahaman konsep siswa rendah.

Dari permasalahan yang dialami saat pandemi covid 19 ini. Reading infusion dijadikan sebagai strategi dalam membantu siswa memahami konsep. Reading infusion adalah bahan bacaan yang mempermudah siswa dalam membedakan antara konsep yang benar dan salah yang dibuat secara per konsep dengan penjelasan secara lebih mendalam berdasarkan fenomena yang ada disekitar lingkungan siswa
(Rayon, Leo Sutrisno, 2016). Menurut (Sarniti, 2018) reading infusion yaitu beirsi fenomena yang terjadi disekitar lingkungan sehari-hari yang berkaitan dengan konsep yang dipelajari. Serta (Gusliana, 2014) juga menyatakan bahwa reading infusion adalah salah satu cara yaitu dengan memberikan bahan bacaan berupa fenomena yang terjadi dalam kehidupan sehari-hari yang berkaitan dengan konsep yang dipelajari diawal pembelajaran, serta siswa diminta untuk mensintesis apa yang ia dapatkan dari bahan bacaan tersebut. Dengan demikian, dapat disimpulkan bahwa reading infusion adalah bahan bacaan yang diberikan diawal pembelajaran yang dibuat secara per konsep berdasarkan peristiwa yang terjadi dalam kehidupan sehari-hari yang berkaitan dengan konsep yang akan dipelajari.

Pentingnya reading infusion dipandemi covid-19 ini dikarenakan bahan bacaan berupa reading infusion dapat membantu siswa dalam memahami konsep suhu dan kalor. Menurut (Rayon, Leo Sutrisno, 2016) dengan menggunakan strategi reading infusion dapat dikategorikan efektif dengan tingkat efektivitas yang tinggi dan membantu siswa dalam memahami konsep yang benar, dengan demikian siswa dapat dengan mudah memahami materi serta dapat mengingat materi tersebut dalam jangka waktu yang lama. Kelebihan dari reading infusion yaitu siswa lebih mudah membedakan antara konsep yang benar dan salah yang dibuat secara per konsep dan ditambah dengan adanya penjelasan secara lebih mendalam sehingga menyebabkan siswa bisa menerima konsep yang sebenarnya serta reading infusion dibuat berdasarkan fenomena yang ada di sekitar lingkungan siswa dan mempermudah siswa dalam memahami konsep (Rayon, Leo Sutrisno, 2016). Serta (Sarniti, 2018) juga mengatakan kelebihan lain dari reading infusion adalah siswa dapat mengungkapkan konsep awal mereka, lebih mengarah ingin mengetahui kebenaran dari konsep awal tersebut, dan dapat meningkatkan minat baca siswa dalam proses pembelajaran sehingga siswa memahami konsep. Kemudian (Sugiarti, 2017) juga mengungkapkan bahwa 
dengan menggunakan reading infusion siswa mendapatkan suatu informasi dari apa yang dibacanya, proses membentuk pengetahuan dengan menfasilitasi siswa supaya memiliki pengetahuan awal sebelum proses pembelajaran berlangsung, dan menjadi bekal pemahaman yang digunakan dalam proses penyelesaian masalah. Menurut (Gusliana, 2014) juga mengatakan bahwa kelebihan reading infusion yaitu meminimalisir kekhawatiran guru tentang waktu pembelajaran dan pengetahuan siswa tentang membaca sehingga dapat memberikan kesempatan keberhasilan siswa akan lebih baik. Dengan demikian maka kelebihan dari reading infusion dapat menjadi salah satu bahan bacaan yang sesuai untuk mendeskripsikan pemahaman konsep siswa. Artikel ini ingin mendapatkan gambaran tentang seberapa jauh pemahaman konsep siswa dengan bantuan reading infusion. Dengan demikian, data ini bermanfaat bagi peneliti selanjutnya khususnya penelitian yang sama dengan penelitian pemahaman konsep.

Berdasarkan latar belakang tersebut, maka penelitian ini bertujuan untuk mendeskripsikan pemahaman konsep siswa dengan strategi reading infusion pada materi suhu dan kalor.

\section{METODE}

Penelitian dilakukan di SMP Negeri 2 Semparuk tahun ajaran 2020/2021 pada semester ganjil. Penelitian yang digunakan adalah penelitian deskriptif kuantitatif yang bertujuan untuk mendeskripsikan kemampuan pemahaman konsep yang dimiliki siswa. Adapun analisis dalam penelitian ini hanya dilakukan pada taraf deskripsi, yaitu menganalisis dan menyajikan fakta secara sistematis.

Populasi dalam penelitian ini adalah seluruh siswa kelas VIII yang termasuk salah satu dari SMP Negeri Kabupaten Sambas. Sampel dalam penelitian ini adalah satu kelas dari keseluruhan siswa kelas VIII yang terdapat di SMP Negeri Kabupaten Sambas yaitu sebanyak 30 orang. Dalam pengambilan sampel terebut menggunakan teknik convenience sampling. Variabel bebas dalam penelitian ini adalah reading infusion, sementara variabel terikatnya adalah kemampuan pemahaman konsep dengan aspek menafsirkan, menjelaskan, menyimpulkan, membandingkan, mencontohkan, mengklasifikasikan, dan merangkum.

Data yang dikumpulkan menggunakan tes sebanyak 12 soal pemahaman konsep dalam bentuk pilihan ganda beralasan yang sudah divalidasi oleh ahli. Instrumen soal juga sudah diujicobakan dan dianalisis menggunakan uji reliabilitas, daya pembeda, dan tingkat kesukaran sehingga instrumen layak untuk digunakan. Teknik pengumpulan data yang digunakan dalam penelitian ini yaitu tes. Tes ini digunakan untuk mendapatkan gambaran pemahaman konsep siswa mengenai materi suhu dan kalor, adapun pelaksanaan tes tersebut dengan menyisipkan reading infusion.

\section{HASIL DAN PEMBAHASAN}

Data hasil perhitungan tes kemampuan pemahaman konsep siswa yang menyisipkan reading infusion dapat dilihat pada gambar berikut.

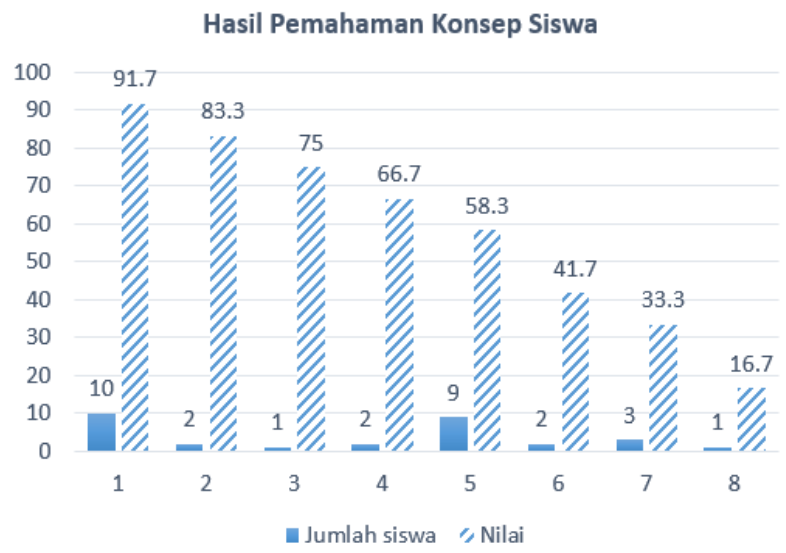

Gambar 1. Hasil Pemahaman Konsep Siswa dengan Reading Infusion

Berdasarkan gambar 1, hasil pemahaman konsep siswa dengan reading infusion yang diikuti oleh 30 siswa menggambarkan bahwa 10 siswa mendapatkan nilai 91,7, 2 siswa mendapatkan 
nilai 83,3 , dan 1 siswa mendapatkan nilai 75 sehingga 13 siswa tersebut dikategorikan memahami konsep. Kemudian, 2 siswa mendapatkan nilai 66,7, 9 siswa mendapatkan nilai 58,3, 2 siswa mendapatkan nilai 41,7, 3 siswa mendapatkan nilai 33,3, dan 1 siswa mendapatkan nilai 16,7 sehingga 13 siswa dikategorikan memahami konsep serta 17 siswa dikategorikan tidak memahami konsep. Peneliti juga melakukan wawancara dengan menanyakan secara garis besar terkait dengan reading infusion yang mempengaruhi nilai mereka.

Data hasil wawancara dengan siswa yang memahami konsep dapat dilihat pada tabel berikut.

Tabel 1. Lampiran langsung hasil diskusi atau tanya jawab siswa yang nilainya menjadi lebih tinggi

\begin{tabular}{|c|c|c|}
\hline \multirow{2}{*}{ No } & \multicolumn{2}{|c|}{ Hasil tanya jawab siswa dan peneliti } \\
\hline & peneliti & siswa \\
\hline 1 & $\begin{array}{l}\text { Mengapa nilai } \\
\text { siswa menjadi } \\
\text { lebih tinggi } \\
\text { setelah } \\
\text { disisipkan } \\
\text { bahan bacaan } \\
\text { terhadap } \\
\text { materi suhu } \\
\text { dan kalor? }\end{array}$ & $\begin{array}{l}\text { Karena dengan membaca } \\
\text { bahan bacaan yang } \\
\text { disisipkan membuat siswa } \\
\text { menjadi paham dan } \\
\text { sangat membantu dalam } \\
\text { mengerjakan soal, hal ini } \\
\text { dikarenakan pada bahan } \\
\text { bacaan tersebut } \\
\text { pembahasannya } \\
\text { berkaitan dalam } \\
\text { kehidupan sehari-hari } \\
\text { yang disertai gambar. }\end{array}$ \\
\hline 2 & $\begin{array}{l}\text { Apakah siswa } \\
\text { berminat } \\
\text { terhadap } \\
\text { bahan } \\
\text { bacaan? }\end{array}$ & $\begin{array}{l}\text { Ya, siswa berminat } \\
\text { terhadap bahan bacaan. }\end{array}$ \\
\hline 3 & $\begin{array}{l}\text { Bagaimanakah } \\
\text { bahan bacaan } \\
\text { yang } \\
\text { diberikan, } \\
\text { menarik atau } \\
\text { tidak? }\end{array}$ & Sangat menarik \\
\hline
\end{tabular}

Dari wawancara yang dilakukan dengan siswa yang memahami konsep dapat disimpulkan bahwa siswa tertarik dengan reading infusion (bahan bacaan) karena sangat menarik, dimana pembahasannya berkaitan dalam kehidupan sehari-hari yang disertai gambar sehingga mudah dimengerti, membantu serta memudahkan siswa dalam menjawab soal dan rata-rata siswa yang memahami konsep berminat dalam membaca bahan bacaan maka dari itu siswa tersebut dapat memahami konsep.

Peneliti juga melakukan wawancara dengan siswa yang kurang memahami konsep, yaitu dengan pertanyaan sama. Data hasil wawancara dengan siswa yang kurang memahami konsep dapat dilihat pada tabel berikut.

Tabel 2. Lampiran langsung hasil diskusi atau tanya jawab siswa yang nilainya menjadi lebih

\begin{tabular}{|c|c|c|c|}
\hline \multirow{2}{*}{ No } & \multicolumn{3}{|c|}{ rendah } \\
\hline & peneliti & siswa & \\
\hline 1 & $\begin{array}{lr}\text { Mengapa } & \text { nilai } \\
\text { siswa menjadi lebih } \\
\text { rendah setelah } \\
\text { disisipkan bahan } \\
\text { bacaan terhadap } \\
\text { materi suhu dan } \\
\text { kalor? }\end{array}$ & $\begin{array}{l}\text { Karena } \\
\text { membaca } \\
\text { bacaan } \\
\text { disisipkan } \\
\text { siswa } \\
\text { kesulitan } \\
\text { memahami } \\
\text { pada bahan }\end{array}$ & $\begin{array}{r}\text { dengan } \\
\text { bahan } \\
\text { yang } \\
\text { membuat } \\
\text { merasa } \\
\text { dalam } \\
\text { materi } \\
\text { bacaan. }\end{array}$ \\
\hline 2 & $\begin{array}{l}\text { Apakah siswa } \\
\text { berminat terhadap } \\
\text { bahan bacaan? }\end{array}$ & $\begin{array}{l}\text { Ya, siswa } \\
\text { terhadap } \\
\text { bacaan }\end{array}$ & $\begin{array}{r}\text { berminat } \\
\text { bahan }\end{array}$ \\
\hline 3 & $\begin{array}{l}\text { Bagaimanakah } \\
\text { bahan bacaan yang } \\
\text { diberikan, menarik } \\
\text { atau tidak? }\end{array}$ & menarik & \\
\hline
\end{tabular}

Dari wawancara yang dilakukan dengan siswa yang kurang dalam memahami konsep dapat disimpulkan bahwa siswa tersebut berminat pada bahan bacaan karena reading infusion menarik dan bagus yang mana berkaitan dalam kehidupan sehari-hari, akan tetapi siswa masih 
mengalami kesulitan menjawab soal dikarenakan sulitnya memahami materi pada bahan bacaan.

Hal ini didukung oleh (Sarniti, 2018) bahwa dengan strategi reading infusion menggambarkan nilai rata-rata tiap konsep dan tiap peserta didik sebesar $65,48 \%$ dan $68,50 \%$ serta besar efektivitas penggunaan reading infusioan SQ3R untuk meremediasi miskonsepsi peserta didik di SMP Negeri 3 Sungai Raya pada materi hukum Archimedes sebesar 66,36 \% (sedang). Hal ini juga diperkuat oleh (Rayon, Leo Sutrisno, 2016) yang menyatakan bahwa dengan strategi reading infusion yang dipadukan dengan tekhnik membaca dapat memudahkan siswa dalam memahami materi serta dapat mengingat materi dengan jangka waktu yang lama.

\section{SIMPULAN}

Reading infusion dapat dijadikan sebagai bahan bacaan dalam pembelajaran agar siswa dapat dalam memahami konsep. Hal ini ditujukan dengan hasil penelitian yang diperoleh mendskipsikan bahwa rata-rata pemahaman konsep siswa dengan strategi reading infusion sebesar 67,22 serta 13 siswa yang memahami konsep sedangkan 17 siswa lainnya belum menguasai konsep. Kemudian gambaran dari wawancara pada 13 siswa yang memahami konsep menyatakan bahwa mereka tertarik dengan reading infusion karena sangat menarik, dimana pembahasannya berkaitan dalam kehidupan sehari-hari yang disertai gambar sehingga mudah dimengerti serta membantu dan memudahkan siswa dalam menjawab soal dan rata-rata siswa tersebut berminat pada bahan bacaan. Serta hasil wawancara dengan siswa yang kurang menguasai konsep menggambarkan bahwa reading infusion bagus dan menarik yang mana berkaitan dengan kehidupan sehari-hari, akan tetapi siswa merasa kesulitan dalam menjawab soal karena kurang memahami materi pada bahan bacaan.

\section{DAFTAR PUSTAKA}

(SUARA KALBAR) Dina Prihatini Wardoyo, diko E. (2020). Sekolah diliburkan dan masyarakat silahkan berangkat tapi jangan datang lagi ke kalbar. Diakses Pada , dari. 15 Maret. https://www.suarakalbar.co.id/2020/03/sutarmidjisekolah-diliburkan-plbn-dan.html

(Suara Pemred), S. (2020). Siswa belajar dirumah hingga akhir semester, sekolah fasilitasi pendaftaran via online. 9 Juni. https://www.suarapemredkalbar.com/read/sambas /09062020/siswa-belajar-di-rumah-hingga-akhirsemestersekolah-fasilitasi-pendaftaran-via-online

Gusliana, G. (2014). Strategi Inquiry Menggunakan Reading Infusion dan Science Reflective Journal Writing Kaitannya Dengan Literasi Sains dan Kemampuan Kognitif Siswa. Journal of Chemical Information and Modeling, 53(9), 9-27. https://doi.org/10.1017/CBO9781107415324.004

Kusumawati, I., Kahar, M. S., Khoiri, A., \& Mursidi, A. (2019). Differences analysis understanding the concept of students between the three islands (Java, Kalimantan, Papua) through multiple representations approaches to the material of Time Dilation. Journal of Physics: Conference Series, 1153(1). https://doi.org/10.1088/17426596/1153/1/012145

Lorin W. Anderson, \& Krathwohl, D. R. (2010). Kerangka Landasan Untuk Pembelajaran (Revisi). PUSTAKA BELAJAR.

Mariana, N. (2017). Penerapan Model Pembelajaran Levels Of Inquiry (LOI) Pada Materi Fluida Statis untuk Meningkatkan Pemahaman Konsep dan Penalaran IImiah Siswa SMP Satu Atap. PendidikanIndonesia.

Nahdi, D. S., Yonanda, D. A., \& Agustin, N. F. (2018). Upaya Meningkatkan Pemahaman Konsep Siswa Melalui Penerapan Metode Demonstrasi pada Mata Pelajaran IPA. Jurnal Cakrawala Pendas, 4(2).

Peraturan Menteri Pendidikan dan Kebudayaan Nomor 21 Tahun 2016 Tentang Standar Isi Pendidikan Dasar dan Menengah, 62 (2016).

Rayon, Leo Sutrisno, E. O. (2016). Efektivitas Penggunaan Reading Infusion SQ3R Untuk Meremediasi Miskonsepsi Siswa SMK Tentang Gerak Jatuh Bebas. In Skripsi. Pontianak: FKIP UNTAN (Vol. 23, Nomor 45). TANJUNGPURA.

Rendra Oxtora, P. (Antara). (2020). Disdik Kalbar evaluasi proses belajar daring selama COVID-19. 
28

https://kalbar.antaranews.com/berita/420664/disd k-kalbar-evaluasi-proses-belajar-daring-selamacovid-19

Sarniti, E. K. A. (2018). Penggunaan Reading Infusion SQ3R Meremediasi Miskonsepsi Peserta Didik pada Materi Hukum Archimedes di SMP. Studi, Program Fisika, Pendidikan Pendidikan, Jurusan
Dan, Matematika Keguruan, Fakultas IImu, D A N Tanjungpura, Universitas.

Sugiarti, T. (2017). Penerapan Model Pembelajaran Problem Based Learning (Pbl) dengan Strategi Reading Infusion untuk Meningkatkan Keterampilan Abad Ke-21 (4C) Siswa Smk pada Materi Suhu Kalor. 21. 